\title{
Microwave synthesis and thermal properties of polyacrylate derivatives containing itaconic anhydride moieties
}

\author{
Sameh M Osman ${ }^{1 \dagger}$, Mohamed H El-Newehy ${ }^{1,2^{*} \dagger}$, Salem S Al-Deyab ${ }^{1 \dagger}$ and Ayman El-Faham ${ }^{1,3^{* \dagger}}$
}

\begin{abstract}
Background: Microwave irradiation as an alternative heat source is now a well-known method in synthetic chemistry. Microwave heating has emerged as a powerful technique to promote a variety of chemical reactions, offering reduced pollution, low cost and offer high yields together with simplicity in processing and handling. On the other hand, copolymers containing both hydrophilic and hydrophobic segments are drawing considerable attention because of their possible use in biological systems. Various copolymer compositions can produce a very large number of different arrangements, producing materials of varying chemical and physical properties. Thus, the hydrophilicity of copolymers can be modified by changing the amount of incorporated itaconic anhydride.

Results: A series of methyl methacrylate (MMA) and acrylamide (AA) copolymers containing itaconic anhydride (ITA) were synthesized by microwave irradiation employing a multimode reactor (Synthos 3000 Aton Paar, GmbH, $1400 \mathrm{~W}$ maximum magnetron) as well as conventional method. The thermal properties of the copolymers were evaluated by different techniques. Structure-thermal property correlation based on changing the itaconic anhydride ratio was demonstrated. Results revealed that the incorporation of itaconic anhydride into the polymeric backbone of all series affect the thermal stability of copolymers. In addition, the use of the microwave method offers high molecular weight copolymers which lead eventually to an increase in thermal stability.

Conclusions: Microwave irradiation method showed advantages for the produced copolymers compared to that prepared by conventional method, where it can offer a copolymer in short time, high yield, more pure compounds and more thermally stable copolymers, rather than conventional method. Also, microwave irradiation method gives higher molecular weight due to prevention of the chain transfer. Moreover, as the itaconic anhydride content increases the thermal stability and $T_{g}$ increase due to the decrease in the crystallinity.
\end{abstract}

\section{Background}

Microwave-assisted organic synthesis has been recognized as one of the most interesting areas of current chemical research [1-5]. Microwave heating has emerged as a powerful technique to promote a variety of chemical reactions, offering reduced pollution, low cost and offer high yields together with simplicity in processing and handling [1,6-11]. The application of microwave irradiation to organic synthesis has been the focus of considerable attention in recent

\footnotetext{
* Correspondence: melnewehy@hotmail.com; aymanel_faham@yahoo.com ${ }^{\dagger}$ Equal contributors

'Petrochemical Research Chair, Department of Chemistry, College of Science, King Saud University, P.O. Box 2455, Riyadh 11451, Saudi Arabia

2Department of Chemistry, Faculty of Science, Tanta University, Tanta 31527 Egypt

Full list of author information is available at the end of the article
}

years and is becoming an increasingly popular technology [12-19]. Recently, there has been growing interest in applying microwave irradiation to polymer synthesis [20-23] as it can accelerate many syntheses providing selective activation with short start-up phase and can allow fast optimization of reactions.

Itaconic anhydride (ITA) is an unsaturated dicarbonic organic anhydride with one carbonyl group conjugated to the methylene group. It can be regarded as a substituted acrylic or methacrylic derivatives. In addition, it can be obtained from renewable resources [24,25]. Also, it can be polymerized [26,27] or copolymerized with various other monomers by free radical reactions [28-33].

As a result of increasing studies of acrylate derivatives and itaconic acid polymers or copolymers, various methods
(C) Chemistry Central

(C) 2012 Osman et al.; licensee Chemistry Central Ltd. This is an Open Access article distributed under the terms of the Creative Commons Attribution License (http://creativecommons.org/licenses/by/2.0), which permits unrestricted use, distribution, and reproduction in any medium, provided the original work is properly cited. 
Table 1 Yield \% of MMA/ITA and AA/ITA copolymers using microwave irradiation

\begin{tabular}{|c|c|c|c|c|c|}
\hline Method & Copolymer Code & MMA/ITA ratio & MMA (mmol) & ITA (mmol) & Yield (\%) \\
\hline Conventional & PMITA 1 & 10: 2 & 50 & 10 & 44.6 \\
\hline \multirow[t]{3}{*}{ Microwave } & PMITA 4 & 10: 1 & 100 & 10 & 76.9 \\
\hline & PMITA 5 & 10: 2 & 100 & 20 & 86.0 \\
\hline & PMITA 6 & 10: 4 & 100 & 40 & 63.8 \\
\hline Method & Copolymer Code & AA/ITA ratio & $\mathrm{AA}(\mathrm{mmol})$ & ITA (mmol) & Yield (\%) \\
\hline Conventional & PAITA 2 & 10: 4 & 50 & 20 & 09.3 \\
\hline \multirow[t]{3}{*}{ Microwave } & PAITA 7 & 10: 1 & 50 & 5 & 92.5 \\
\hline & PAITA 8 & 10: 2 & 50 & 10 & 69.8 \\
\hline & PAITA 9 & 10: 4 & 100 & 40 & 57.0 \\
\hline
\end{tabular}

for the synthesis of these polymers and their copolymers with the monomers such as acrylonitrile, styrene and acrylic esters have been reported, in most cases radical polymerizations [34-42]. Various copolymer compositions can produce a very large number of different arrangements, producing materials of varying chemical and physical properties. Thus, the hydrophilicity of copolymers can be modified by changing the amount of incorporated itaconic anhydride [27].

The present work described copolymerization of acrylic monomers such as methyl methacrylate (MMA) and acrylamide (AA) with different ratios of itaconic anhydride (ITA) through free radical copolymerization in the presence of $\alpha, \alpha^{\prime}$-azobisisobutyro nitrile (AIBN). Copolymerizations were carried out in both conventional and microwave conditions. The chemical structure of the prepared copolymers was confirmed by FTIR and size exclusion chromatography (SEC) and the thermal stability were studied using thermogravimetric analysis (TGA) and differential scanning calorimetry (DSC).

\section{Experimental}

\section{Materials \& Equipments}

Itaconic anhydride (ITA) was purchased from Fluka. Acrylamide (AA) was purchased from LKB. Methyl methacrylate (MMA) was purchased from M \& B. $\alpha, \alpha^{`}-$ Azobisisobutyronitrile (AIBN) was purchased from Aldrich and was recrystallized from absolute ethanol before use. All solvents were dried before use.

The microwave irradiation employing a multimode reactor (Synthos 3000, Aton Paar GmbH, 1400 W maximum magnetron) was used to prepare the copolymers. Fourier transform infrared spectroscopy (FTIR) Spectra was recorded on Nicolet 560 Magna spectrometer. Thermal properties of the copolymers were examined through using thermogravimetric analysis (TGA) under nitrogen, from room temperature to $800^{\circ} \mathrm{C}$ with heating rate of $10^{\circ} \mathrm{C} / \mathrm{min}$ and differential scanning calorimetery (DSC) which was carried on TA-Q500 in which Specimens of (5-10 mg) were encapsulated in aluminum pans and were heated or cooled between $-25^{\circ} \mathrm{C}$ and $400^{\circ} \mathrm{C}$ under dry nitrogen atmosphere with heating rate of $10^{\circ} \mathrm{C}$ /min. Number-average molecular weight $\left(M_{n}\right)$ and molecular weight distribution $\left(M_{w} / M_{n}\right)$ were estimated by size exclusion chromatography (SEC) which was carried on Viscotek, HT-GPC. Polystyrene standards were employed for calibration. The analysis was performed at $35^{\circ} \mathrm{C}$ using high-performance liquid chromatographygrade THF as the eluent. Polystyrene standards were used to calibrate the molecular weight.

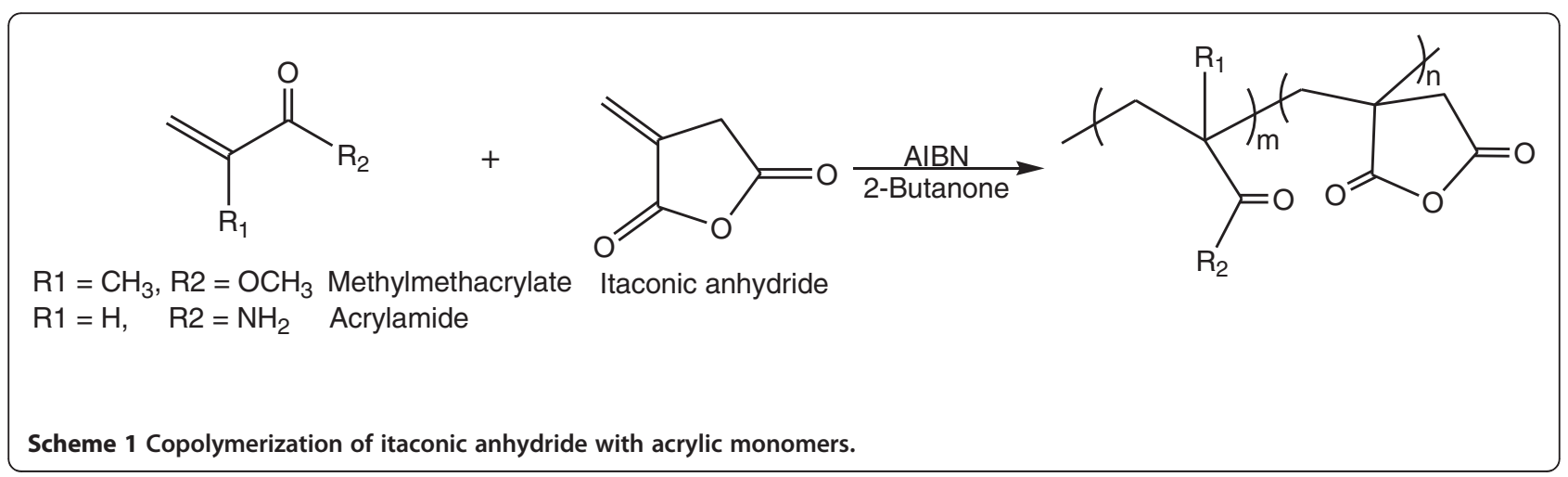




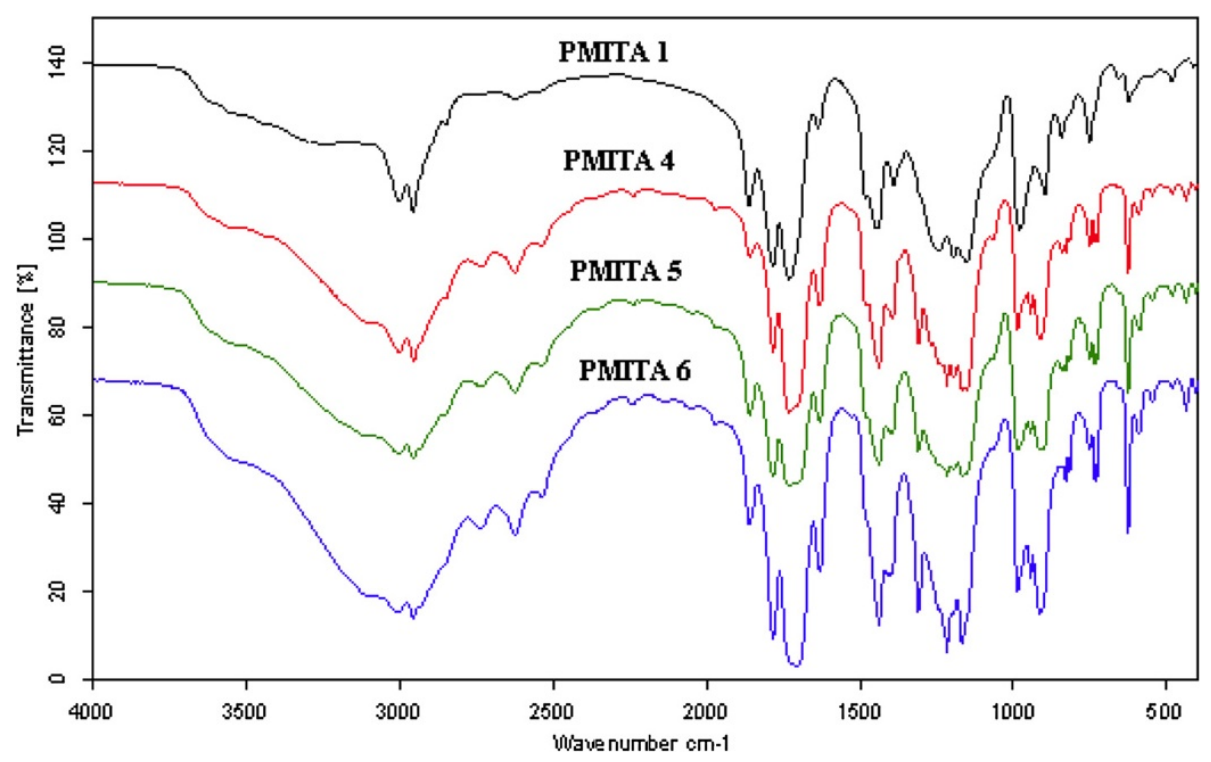

Figure 1 FT-IR spectra of PMITAs copolymers.

\section{Synthesis of Copolymers}

\section{General Procedure for Conventional Method}

In a general procedure, in a three-neck round bottomed flask fitted with a condenser, methyl methacrylate (MMA) (5.00 g, $50.0 \mathrm{mmol}$ ) or acrylamide (AA) (3.55 g, $50.0 \mathrm{mmol}$ ) was mixed with itaconic anhydride (ITA) $(1.12 \mathrm{~g}, 10.0 \mathrm{mmol})$ in 2-butanone $(20 \mathrm{~mL})$. The reaction mixture was thoroughly purged with nitrogen for 10 min. Copolymerization was initiated by adding AIBN $(0.1 \mathrm{~g}, 0.01 \% \mathrm{w} / \mathrm{w})$ and then was heated at $60^{\circ} \mathrm{C}$, under nitrogen atmosphere for $24 \mathrm{~h}$. The reaction was cooled down to room temperature, and then the copolymer was precipitated in diethyl ether. The precipitated copolymer was filtered, washed by excess of diethyl ether and was dried in oven under vacuum at $40^{\circ} \mathrm{C}$ for $24 \mathrm{~h}$, Table 1 .

\section{General Procedure for Microwave-Assisted Synthesis}

Employing a multimode reactor (Synthos 3000, Aton Paar $\mathrm{GmbH}, 1400 \mathrm{~W}$ maximum magnetron); the initial step was conducted with 4-Teflon vessels rotor (MF 100) that allow processing four reactions under the same conditions. Each vessel has itaconic anhydride (ITA) was mixed with methyl methacrylate (MMA) or acrylamide (AA) in specific ratio $(10: 1,10: 2$, and 10:4), in the presence of $(0.1 \mathrm{~g})$ AIBN and

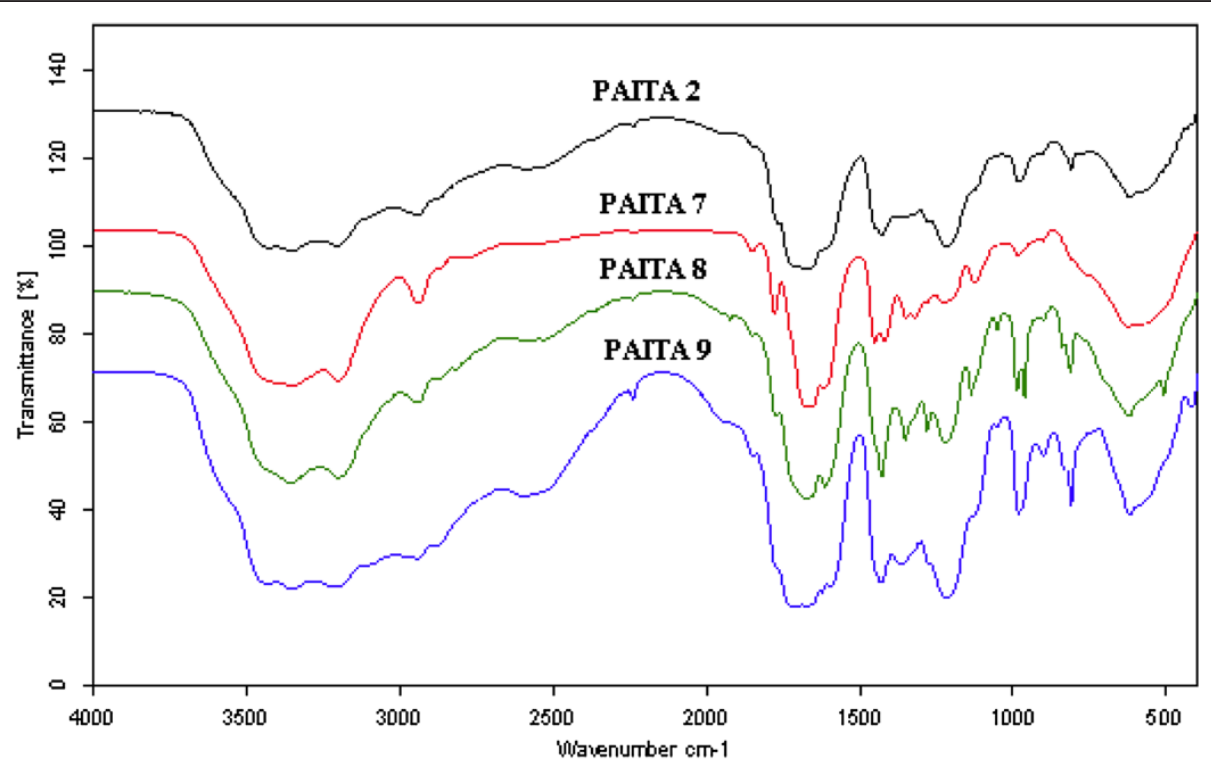

Figure 2 FT-IR spectra of PAITAs copolymers. 


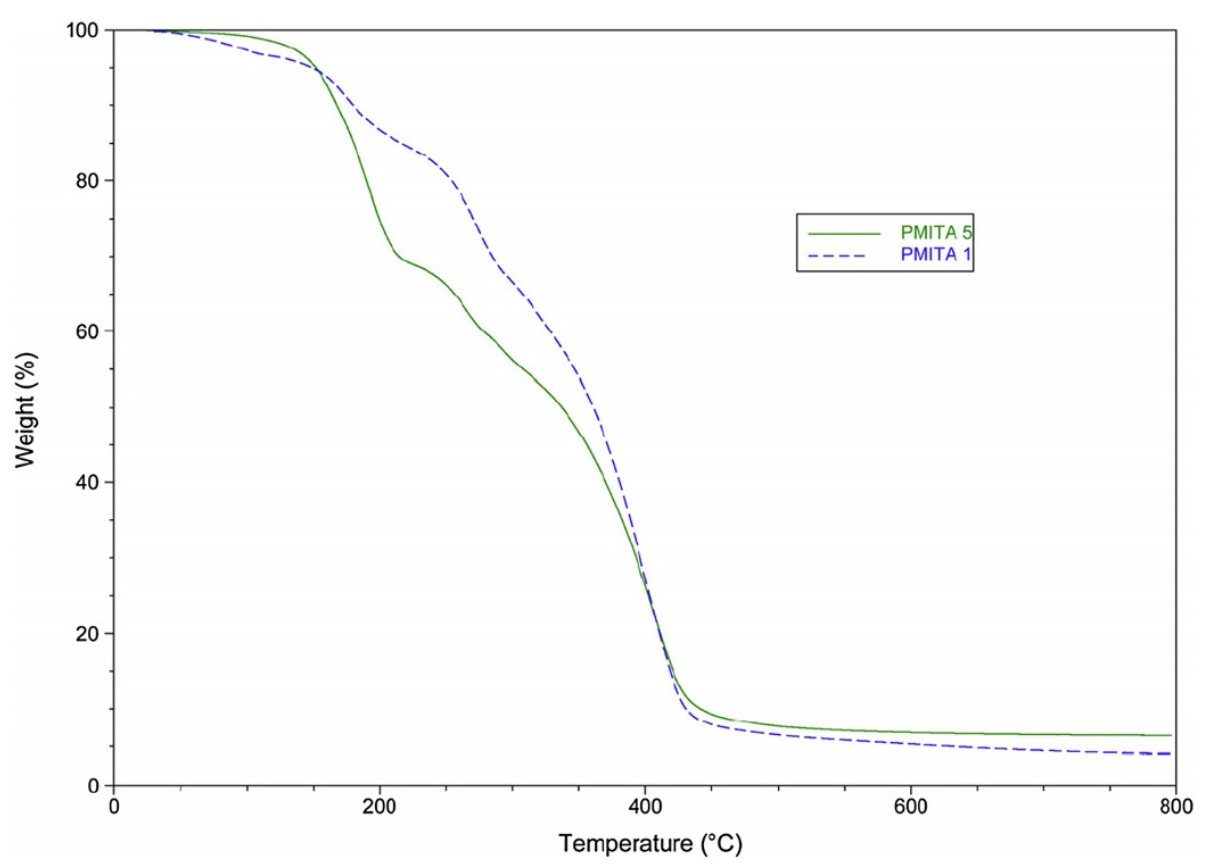

Figure 3 TGA of copolymers PMITA1 and PMITA5.

2-butanone as a solvent (Table 1). The individual vessels were purged with nitrogen gas for $10 \mathrm{~min}$ and then were placed in the corresponding rotor, fixed by screwing down the upper rotor place, and finally the rotor was closed with a protective hood. After heating the vessels for $5 \mathrm{~min}$. at $140^{\circ} \mathrm{C}$ and hold at the same temperature for $5 \mathrm{~min}(\sim 2 \mathrm{bar}$ pressure, $400 \mathrm{~W})$. Cooling was accomplished by a fan
(5 min). The final product was washed with diethyl ether, and was dried in oven under vacuum at $40^{\circ} \mathrm{C}$ for $24 \mathrm{~h}$.

\section{Results and Discussion}

The copolymerization reaction of methyl methacrylate and acrylamide with itaconic anhydride was carried out by two different methods: a) conventional method using of 2-

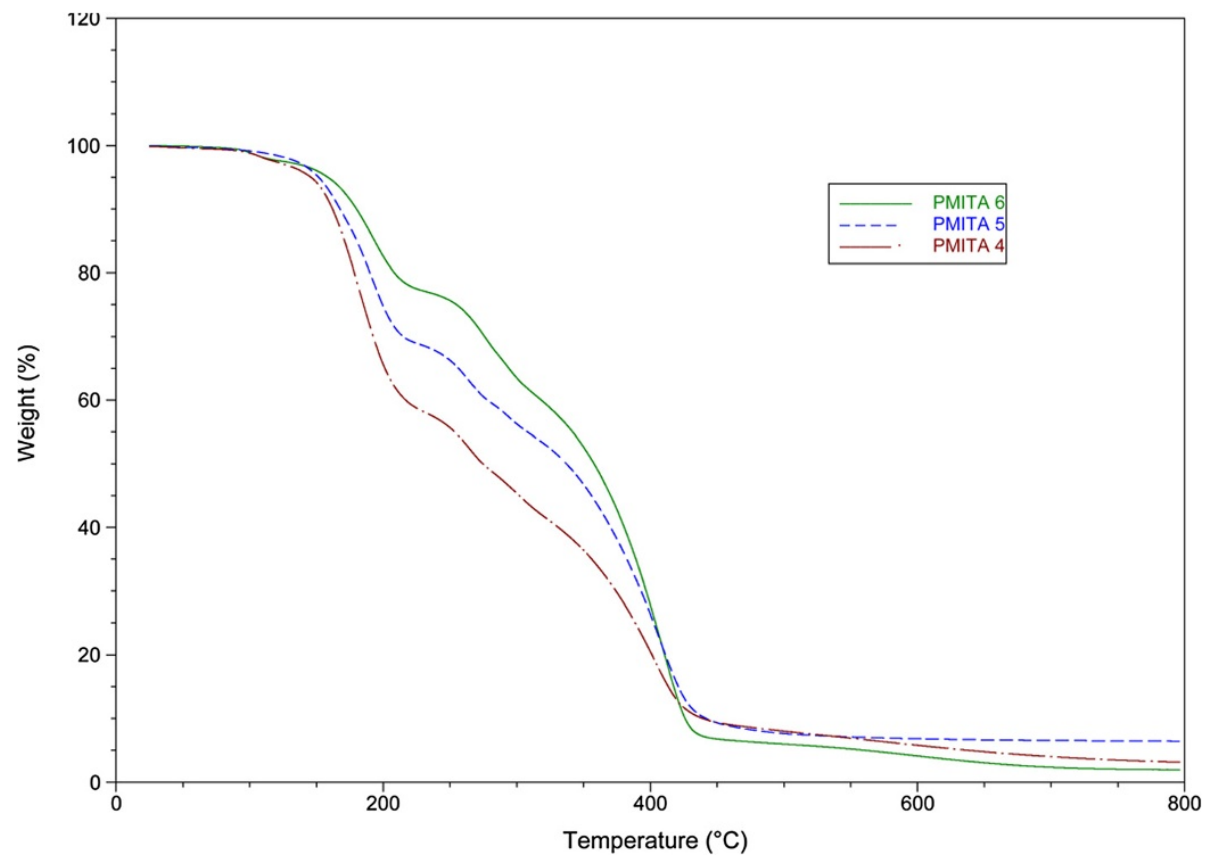

Figure 4 TGA thermogram of copolymers PMITA4-6. 


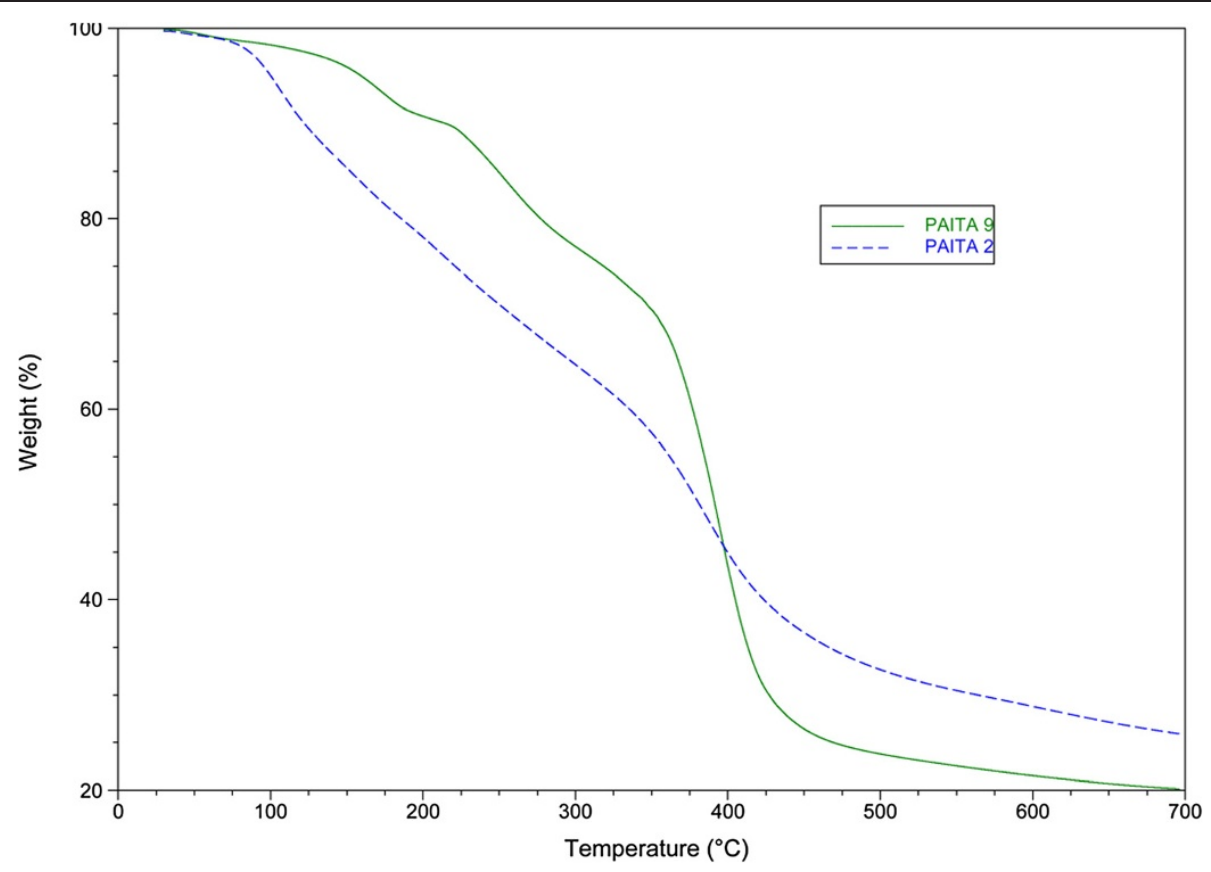

Figure 5 TGA thermogram of copolymers PAITA2 and PAITA9.

butanone as a solvent and AIBN as initiator for free radical polymerization at $60^{\circ} \mathrm{C}$, under nitrogen atmosphere for $24 \mathrm{~h}$ and b) Employing a microwave synthesis using a multimode reactor (Synthos 3000, Aton Paar GmbH, 1400 W maximum magnetron), in the presence of AIBN for $5 \mathrm{~min}$. at $140^{\circ} \mathrm{C}$ and $400 \mathrm{~W}$, Scheme 1 . The prepared copolymers were characterized using FT-IR spectra, TGA, DSC, SEC, and elemental microanalysis.

\section{Fourier Transform Infrared Spectroscopy (FT-IR)}

The FTIR spectra of itaconic anhydride copolymers, Figures 1 and 2 showed the absorption peaks for the ITA at

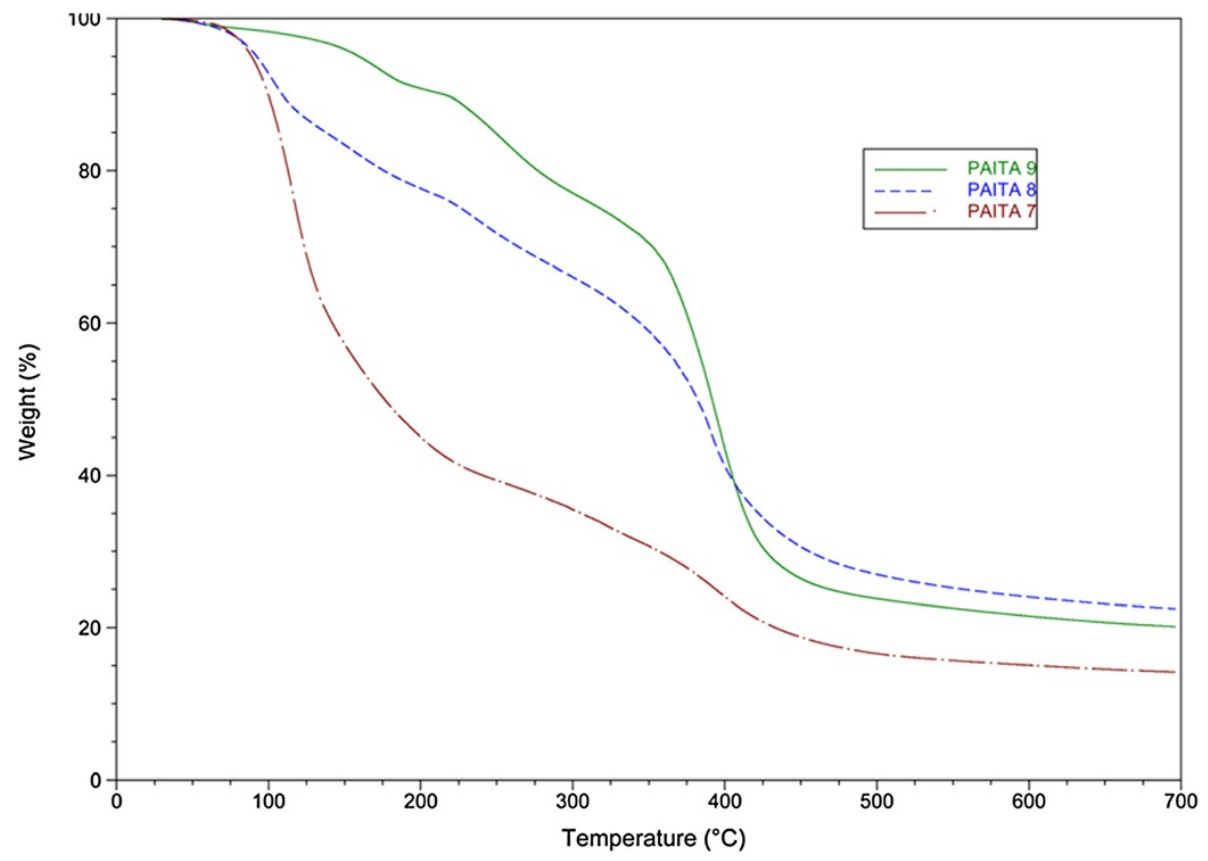

Figure 6 TGA thermogram of copolymers PAITA7-9. 
Table 2 Information derived from TGA measurements of degradation of copolymers PMITA 1, 4-6 and PAITA 2, 7-9

\begin{tabular}{lllll}
\hline Copolymer Code & $\boldsymbol{T}_{\text {onset }}\left({ }^{\circ} \mathrm{C}\right)$ & $\boldsymbol{T}_{\boldsymbol{m a x}}\left({ }^{\circ} \mathrm{C}\right)$ & $\boldsymbol{T}_{\mathbf{5 0}}\left({ }^{\circ} \mathrm{C}\right)$ & Residue (\%) \\
\hline PMITA1 & 154 & 363 & 360 & 6.5 \\
PMITA4 & 165 & 369 & 358 & 6.0 \\
PMITA5 & 158 & 365 & 337 & 7.6 \\
PMITA6 & 158 & 367 & 275 & 8.0 \\
PAITA2 & 86 & 351 & 381 & 32.7 \\
PAITA7 & 94 & 371 & 176 & 16.6 \\
PAITA8 & 84 & 366 & 382 & 27.0 \\
PAITA9 & 145 & 366 & 391 & 23.8
\end{tabular}

${ }^{*}$ At $500{ }^{\circ} \mathrm{C}$.

1783 and $1860 \mathrm{~cm}^{-1}(\mathrm{C}=\mathrm{O}$ symmetric and asymmetric stretching of the 5-member anhydride unit), $1662 \mathrm{~cm}^{-1}(\mathrm{C}=$ $\mathrm{C}$ stretching), and $1400 \mathrm{~cm}^{-1}\left(=\mathrm{CH}_{2}\right.$ in plane deformation), and for methyl methacrylate at $1731 \mathrm{~cm}^{-1}(\mathrm{C}=\mathrm{O})$ and for the acrylamide at $1640 \mathrm{~cm}^{-1}$ and at $3349 \mathrm{~cm}^{-1}$ originates from the secondary amines in acrylamide. The anhydride peaks indicate that the anhydride remained intact in the copolymer, and the shift to higher frequency (higher energy) of the ester and amide carbonyl stretch is consistent with the elimination of the conjugation of the vinyl and carbonyl double bonds.

The intensity of the anhydride peaks was increased as the ratio of ITA increased in the copolymer, Figures 1 and 2. Copolymers prepared by both conventional method and microwave irradiation showed the same spectral characterization.

\section{Thermogravimetric Analysis (TGA)}

The thermal properties of the prepared copolymers were evaluated by thermogravimetric analysis (TGA) Figures 3-6, in which the weight of a sample is measured as a function of temperature whilst it is subject to a controlled heating program. Thermal results revealed that the prepared copolymers have high thermal stabilities. Structure thermal property correlation based on changing of the itaconic anhydride ratios, as a single structural modification, demonstrated an interesting connection between itaconic anhydride ratios and thermal properties.

For copolymers PMITA1 \& PMITA5, the thermogram, Figure 3 , showed that the prepared copolymers were degraded in four similar degradation steps. The first step with weight loss of $2.42 \%$ for conventional method at $70-115^{\circ} \mathrm{C}$ and $21.27 \%$ for microwave-assisted method at $130-225^{\circ} \mathrm{C}$ which is attributed to water evaporation and decarboxylation which is more clear in the prepared copolymers by microwave irradiation, respectively. The last stage exhibited subsequent major degradation process between $331-445^{\circ} \mathrm{C}(87.13 \%$, wt loss) and between $331-445^{\circ} \mathrm{C}(80.71 \%$, wt loss) for PMITA1 and PMITA5, respectively.

For the effect of the percentage of itaconic anhydride, Figure 4, the thermogravimetric data showed that the thermal stability of copolymer PMITA6 is higher than both copolymers PMITA4 and PMITA5 due to the increase in the itaconic anhydride content as a bulk group which leads to an increase in the thermal stability.

For copolymers PAITA2 and PAITA9, the thermograms, Figure 5, showed that they were degraded via two main stage degradation processes; the first step for copolymer PAITA2 is between 100 to $110^{\circ} \mathrm{C}$ with weight loss of $7.53 \%$, while the last step occurs in a range of 380 to $440^{\circ} \mathrm{C}$ with weight loss of $62.39 \%$. For copolymer PAITA9, we find the first degradation step is between 115 to $120^{\circ} \mathrm{C}$ with weight loss of $6.19 \%$, while the last degradation step is between 490 to $445^{\circ} \mathrm{C}$ with weight

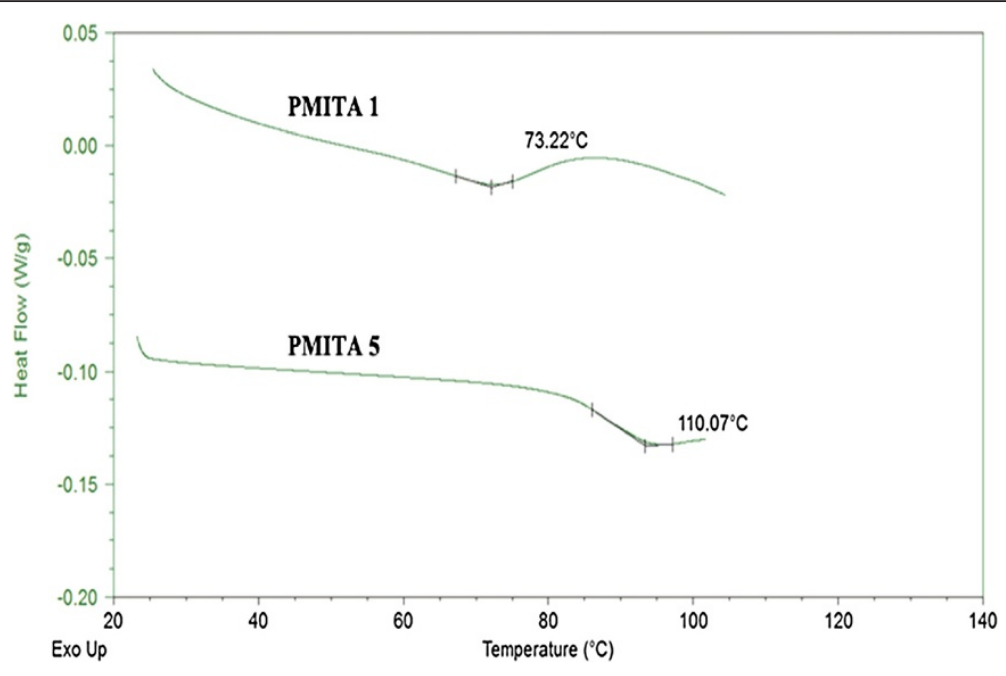

Figure 7 DSC thermogram of copolymers PMITA1 and PMITA5. 


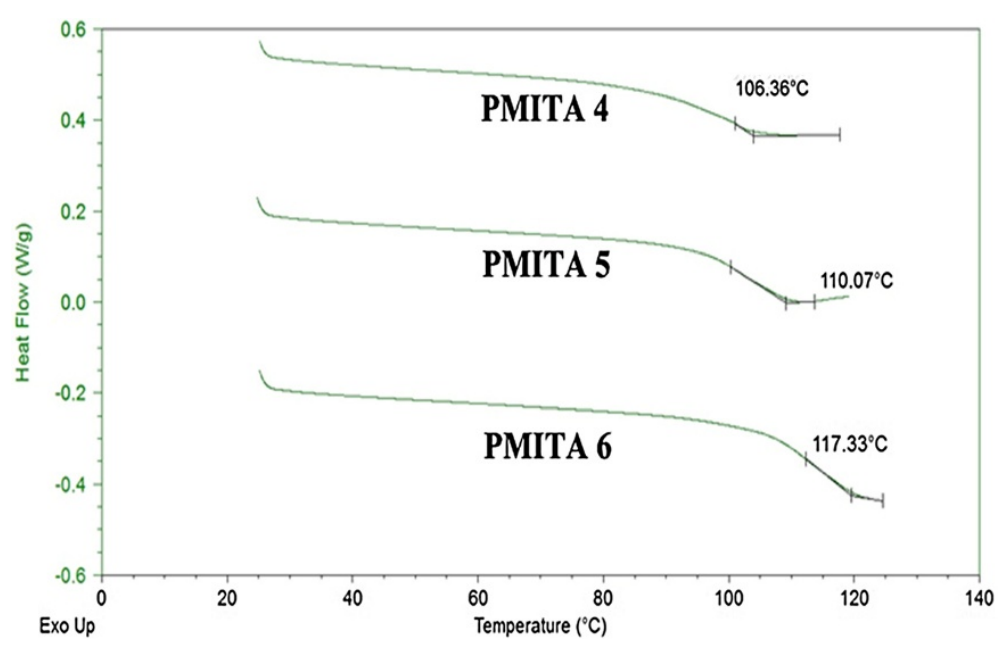

Figure 8 DSC thermogram of copolymers PMITA4-6.

loss of $61.68 \%$. The thermogram showed the major weight loss within the temperature range $331-507^{\circ} \mathrm{C}$ and the temperature for a maximum decomposition was 559 and $661^{\circ} \mathrm{C}$ for copolymers PAITA2 and PAITA9, respectively.

For the effect of the percentage of itaconic anhydride, Figure 6, the thermogravimetric data showed that the thermal stability of copolymer PAITA9 is higher than copolymer PAITA7 due to the increase in the itaconic anhydride content as a bulk group which leads to an increase in the thermal stability as described earlier.

Considerable differences in the thermal decomposition of the prepared copolymers are observed in terms of degradation temperature are shown in (Table 2).
The copolymerization using microwave irradiation led to an increased $T_{\text {onset }}$ of PMITA1 compared to PMITA5 which prepared by conventional method, however, $T_{50}$ and $T_{\max }$ decreased. While on increasing the itaconic anhydride content (PMITA4-6), $T_{\text {onset }}$ and $T_{50}$ decreased and $T_{\max }$ are too close.

Similarly, PAITA2, 7-9, $T_{\text {onset }}, T_{50}$ and $T_{\text {max }}$ increased from PAITA2, which prepared by conventional method, to PAITA9, which prepared by microwave irradiation. The same conclusion was observed with increasing the itaconic anhydride content (PAITA7-9).

This could be explained by that microwave irradiation gave chance for increasing the itaconic anhydride content more than conventional method. As expected from the literature, the molecular weight of the copolymers

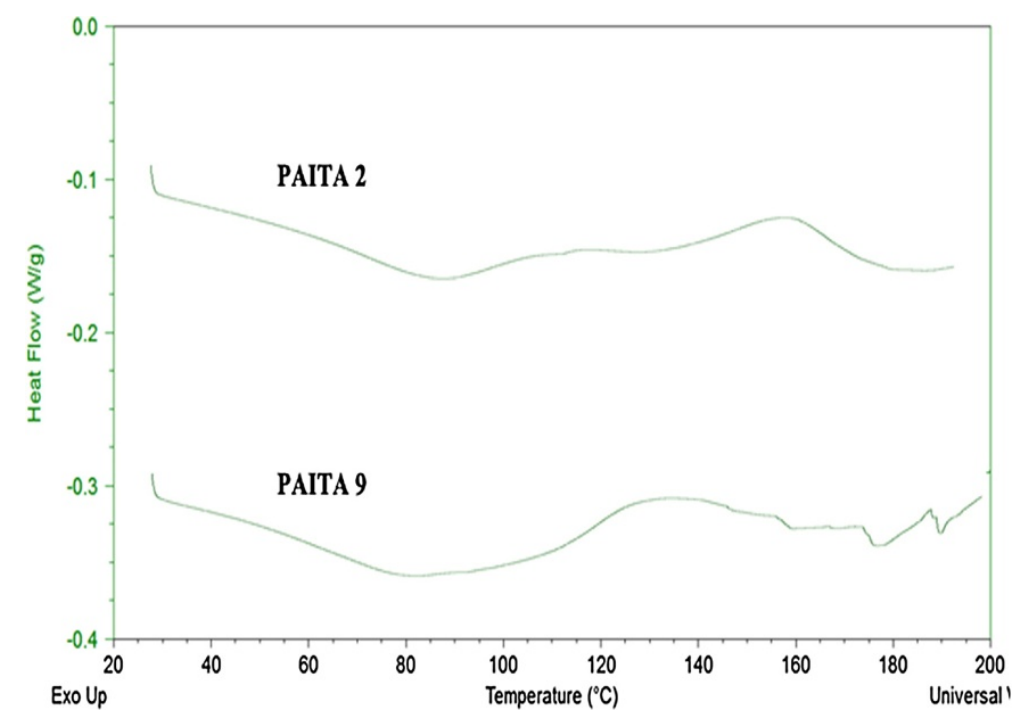

Figure 9 DSC thermogram of copolymers PAITA2 and PAITA9. 


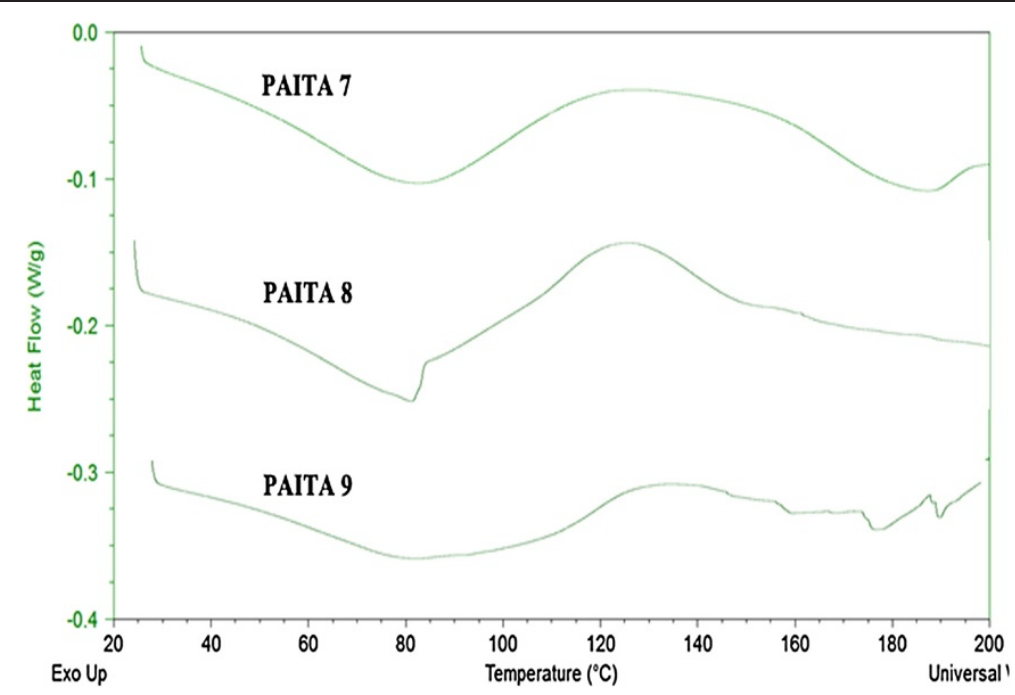

Figure 10 DSC thermogram of copolymers PAITA7-9.

decreased with increasing ITA concentration in the feed, which may be a consequence of the allylic hydrogen in ITA that can act as a chain transfer agent in radical polymerization $[43,44]$.

\section{Differential Scanning Calorimetry (DSC)}

The effect of itaconic anhydride ratio in the prepared copolymers changes on the glass transition temperature $\left(T_{g}\right)$ and the copolymer crystallinity upon thermal treatment were investigated by DSC at a heating rate of $10{ }^{\circ} \mathrm{C} / \mathrm{min}$, and the results are shown in Figures 7-10. The DSC traces, one transition was observed. The glass transition temperature $\left(T_{g}\right)$ was found to be 73 and $110^{\circ} \mathrm{C}$, for copolymers PMITA1 and PMITA5, respectively. It was noticed that $T_{g}$ of copolymer PMITA5 is higher than that of copolymer PMITA1, which gives another evidence for enhancing the thermal properties by using the microwave technique due to increasing in the itaconic anhydride content. On the other hand the glass transition temperature $\left(T_{g}\right)$ was found to be 106,110 , and $117^{\circ} \mathrm{C}$, for copolymers PMITA4, PMITA5, and PMITA6, respectively, Figure 8.
The $T_{g}$ increased as the ITA content increase due to the decrease in crystallinity [45].

Figure 9 showed the DSC thermograms of copolymers PAITA2 and PAITA9 copolymers prepared by conventional and microwave method. Both show no glass transition temperature, but copolymer PAITA2 shows a hump from 30 to $100^{\circ} \mathrm{C}$, this hump is assigned to the evaporation of water attached to the polar amide groups $\mathrm{NH}_{2} \mathrm{CO}$ - [46]. While for copolymer PAITA9 this hump starts from 30 to $120^{\circ} \mathrm{C}$ for the same reason.

Moreover, for the degradation process of the copolymer PAIT2, PAIT7-9 it is clear that the effect of the hydrogen bond so during the first degradation only dehydration followed by deamination process and this stage there is no differences between the prepared polymer by convention method and microwave irradiation while at higher temperature most of the hydrogen bond were broken and the difference in the thermal stabilities and the effect of the ITA was clear [47].

For AA/ITA copolymers series PAITA7-9 prepared by microwave method, the DSC thermograms, Figure 10, showed that copolymers PAITA7-9 has no glass transition

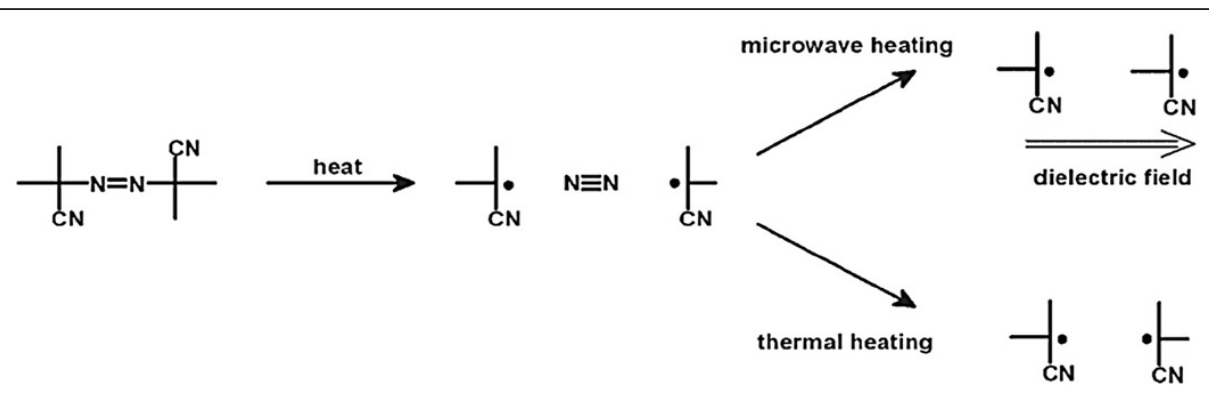

Figure 11 Schematic representation of the direct orientation of radicals that are formed from the decomposition of a, $\alpha^{`}$-azoisobutyronitrile (AIBN) under microwave irradiation [47]. 

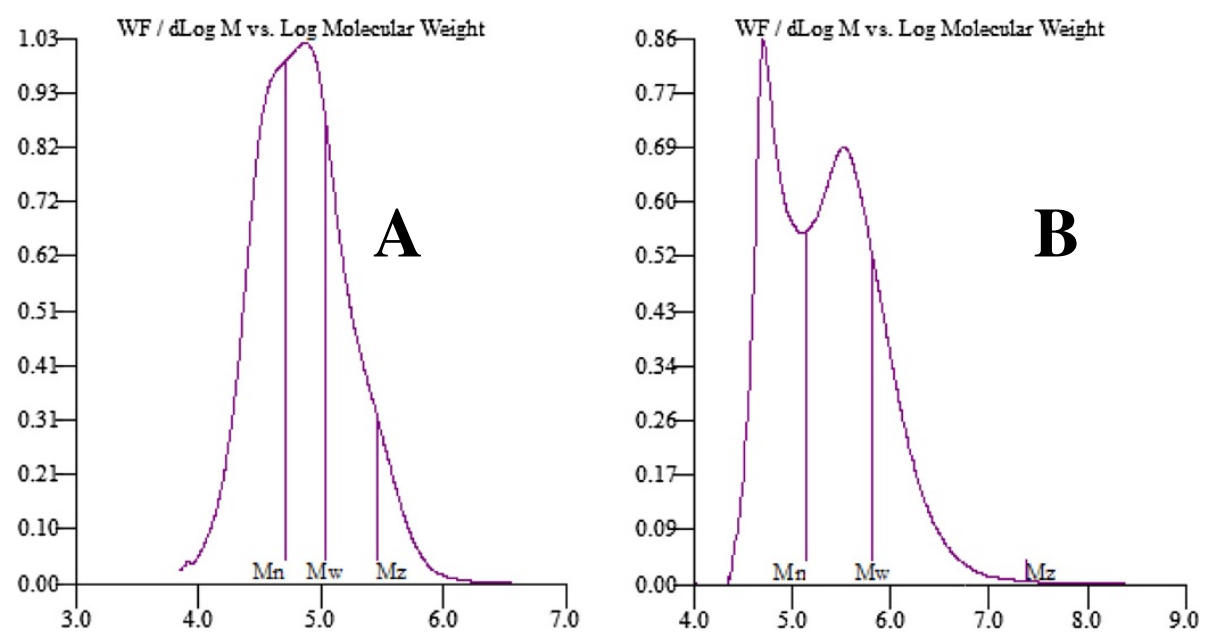

Figure 12 SEC traces of copolymers a) PMITA5, b) PMITA6. For copolymer PMITA5, $M_{n}=140,872, M_{w}=653.924, M_{w} / M_{n}=4.64$. For copolymer PMITA6, $M_{\mathrm{n}}=50,574, M_{\mathrm{w}}=288,871, M_{\mathrm{w}} / M_{\mathrm{n}}=2.14$, which obtained at MMA/ITA ratio 10:2 and 10:4, respectively, in 2-butanone using microwave irradiation.

temperature, the absence of $T_{g}$ may be due to that itaconic anhydride makes a steric hindrance for the segmental motion of the copolymer, which lead to the absence of $T_{g}$.

Generally, the increase in the thermal stability for copolymers prepared by microwave irradiation technique compared to those prepared by conventional method is attributed to the increased radical flux under microwave irradiation as well as increasing of the itaconic anhydride content and prevention of the chain transfer in free radical polymerization. This result from the rapid orientation of the radicals that are formed from the decomposition of the $\alpha, \alpha$-azobisisobutyronitrile as depicted in, Figure $11[43,44,48]$, this orientation reduces the number of direct terminations via recombination of the formed two radical fragments under microwave irradiation and thus cause a higher radical flux. The obtained high radical flux leads to the formation of high molecular weight copolymers, which result in increase in their thermal stability of the copolymers synthesized by microwave irradiation method rather

Table 3 Elemental microanalysis of the prepared copolymers using microwave irradiation

\begin{tabular}{|c|c|c|c|c|c|c|}
\hline \multirow{2}{*}{$\begin{array}{l}\text { Copolymer } \\
\text { code }\end{array}$} & \multicolumn{3}{|c|}{ Calculated (\%) } & \multicolumn{3}{|c|}{ Found (\%) } \\
\hline & $C$ & $\mathrm{H}$ & $\mathbf{N}$ & $C$ & $\mathrm{H}$ & $\mathbf{N}$ \\
\hline PMITA4 & 59.3 & 7.6 & - & 58.6 & 7.8 & - \\
\hline PMITA5 & 58.8 & 7.2 & - & 58.3 & 7.6 & - \\
\hline PMITA6 & 58.0 & 6.6 & - & 55.2 & 5.5 & - \\
\hline PAITA7 & 51.1 & 6.6 & 17.0 & 48.4 & 7.0 & 15.9 \\
\hline PAITA8 & 51.4 & 6.5 & 14.4 & 49.3 & 6.6 & 14.1 \\
\hline PAITA9 & 51.8 & 6.0 & 11.7 & 49.8 & 6.4 & 9.8 \\
\hline
\end{tabular}

than copolymers synthesized by conventional solution polymerization.

\section{The molecular weight and Elemental microanalysis Determination}

The molecular weight of itaconic anhydride copolymers have been studied, again it is obvious that the molecular weight decrease with increasing the ratio of itaconic anhydride in the copolymer with a significant change using microwave irradiation method due to the prevention of chain transfer and increasing of the itaconic anhydride in the copolymer composition (PMITA 5), Figure 12. For SEC measurements, SEC traces showed that for copolymer PMITA5, $M_{n}$ was $140,872 \mathrm{~g} / \mathrm{mol}$ with polydispersity 4.64 , while for copolymer PMITA6, $M_{n}$ was found to be $50,574 \mathrm{~g} / \mathrm{mol}$ with polydispersity of 2.14 .

Moreover Figure 12B not 12A showed a bimodal population in which the first one is related to the formation of itaconic anhydride homopolymer due to the increase in itaconic anhydride ratio.

In addition, the copolymers structures and ratios were confirmed by elemental microanalysis which in a good agreement with the calculated values (Table 3).

\section{Conclusions}

Itaconic anhydride based copolymers with both methyl methacrylate and acrylamide with different ratios were successfully prepared using microwave irradiation technique. For comparison study, similar copolymers were prepared by conventional method. The obtained results showed the advantages of microwave irradiation method over conventional method. Microwave irradiation method offers the possibility of the preparation of copolymer in short time with high yield, high molecular weight and 
high thermal stability. Moreover, as the itaconic anhydride content increases the thermal stability and $T_{g}$ increase due to the decrease in the crystallinity.

\section{Competing interests}

The authors declare that they have no competing interests.

\section{Authors' contributions}

SMO carried out all the experimental work. MHE, SSE and AEF designed the proposed methods and analyzed the data statistically together. All authors read and approved the final manuscript.

\section{Acknowledgment}

This project was supported by King Saud University, Deanship of Scientific Research, College of Science Research Center.

\section{Author details}

${ }^{1}$ Petrochemical Research Chair, Department of Chemistry, College of Science, King Saud University, P.O. Box 2455, Riyadh 11451, Saudi Arabia. ${ }^{2}$ Department of Chemistry, Faculty of Science, Tanta University, Tanta 31527, Egypt.

${ }^{3}$ Alexandria University, Faculty of Science, Chemistry Department, P. O. Box

426 Ibrahimia, Alexandria 12321, Egypt.

Received: 10 April 2012 Accepted: 30 July 2012

Published: 8 August 2012

\section{References}

1. Lidstrom P, Tierney J, Wathey B, Westman J: Microwave-assisted organic synthesis a review. Tetrahedron 2001, 57:9225-9283.

2. Perrux L, Loupy AA: Tentative realization of microwave effects in organic synthesis according to the reaction medium and mechanistic consideration. Tetrahedron 2001, 57:9199-9223.

3. Caddick S: Microwave-assisted organic-reactions. Tetrahedron 1995 51:10403-10432.

4. Matloobi M, Kappe CO: Microwave synthesis in high-throughput environments. Moving from automated sequential to microtiter plate formats. Chim. Oggi. 2007, 2007(25):26-31.

5. Mallakpour S, Rafiee Z: Application of microwave-assisted reactions in step-growth polymerization: A review. Iran. Poly. J. 2008, 17:907-935.

6. Adam D: Out of the kitchen. Nature 2003, 421:571-572.

7. Loupy A: Solvent-free microwave organic synthesis as an efficient procedure for green chemistry. Chimie. 2004, 7:103-112.

8. Lerestif JM, Toupet L, Sun-bandhit S, Tonnard F, Bazureau JP, Hamelin J: A new route to 2-oxazolines, bis-oxazolines, and 2-imidazoline-5ones from imidates using solvent-free cycloadditions: Synthesis, chemical properties, and PM3 MO calculations. Tetrahedron 1997, 53:6351-6364.

9. Varma RS, Dahiya R, Kumar S: Clay catalyzed synthesis of imines and enamines under solvent-free conditions using microwave irradiation. Tetrahedron Lett. 1997, 38:2039-2042.

10. Varma RS: Clay and clay-supported reagents in organic synthesis. Tetrahedron 2002, 58:1235-1255.

11. Karah N: Synthesis and primary cytotoxicity evaluation of new 5nitroindole-2,3-dione derivatives. Eur. J. Med. Chem. 2002, 37:909-918.

12. Kidwai M: Dry media reactions. Pure Appl. Chem 2001, 73:147-151.

13. Raval JP, Desai KR: Synthesis and antimicrobial activity of new triazolopyridinyl phenothiazines. Arkivoc 2005, xiii:21-28

14. Raval JP, Desai KG, Desai KR: Neat reaction technology for the synthesis of 4-oxothiazolidines derived from 2-SHBenzothiazole and antimicrobial screening of some synthesized 4-thiazolidinones. J. Iranian Chem. Soc. 2006, 3:233-241.

15. Raval JP, Desai JT, Desai CK, Desai KR: A comparative study of microwave assisted and conventional synthesis of 2,3-dihydro-2aryl-4-[4-(2-oxo-2H-chromen-3-yl)-1,3-thiazol-2-ylamino]-1,5benzothiazepines and its antimicrobial activity. Arkivoc 2008, xii:233-244.

16. Raval JP, Desai KR: A comparative study of microwave assisted and conventional Synthesis of novel 2-(4-diethylamino-2-hydroxyphenyl)-3substituted-thiazolidin-4-one derivatives. Chemija. 2009, 20:101-108.

17. Raval JP, Patel HV, Patel PS, Patel NH, Desai KR: A rapid, convenient microwave assisted and conventional synthesis of novel azetidin-2-one derivatives as potent antimicrobial agents. Asian J. Res. Chem. 2009, 2:171-177.

18. Al-Hazimi HM, El-Faham A, Ghazzali M, Al-Farhan K: Microwave irradiation: A facile, scalable and convenient method for synthesis of N-phthaloylamino acids. Arab. J. Chem. 2012, 5:285-289.

19. Ghazzali M, El-Faham A, Abd-Megeed A, Al-Farhan K: Microwaveassisted synthesis, structural elucidation and biological assessment of 2-(2-acetamidophenyl)-2-oxo- $\mathrm{N}$-phenyl acetamide and $\mathrm{N}$-(2-(2-oxo-2(phenylamino)acetyl)phenyl)-propionamide derivatives. J. Mol. Str. 2012, 1013:163-167.

20. Jullien $\mathrm{H}$, Valot $\mathrm{H}$ : Polyurethane curing by a pulsed microwave field. Polymer 1985, 26:506-510.

21. 2Silinski B, Kuzmycz C, Gourdenne A: Synthesis under microwaves (2.45 $\mathrm{GHz}$ ) of polyurethane polymers-I. Model study from diisocyanate and polyethertriol prepolymers. Eur. Polym. J 1987, 23:273-277.

22. Imai $Y$, Nemoto $H$, Watanabe $S$, Kakimoto MA: A new facile and rapid synthesis of aliphatic polyamides by microwave assisted polycondensation of $\omega$-amino acids and nylon salts. Polym. J. 1996, 28:256-260.

23. Liu $Y$, Sun $X D$, Xie $X Q$, Scola DA: Kinetics of the crosslinking reaction of a bisnadimide model compound in thermal and microwave cure processes. J. Polym. Sci, Part A, Polym. Chem. 1998, 36:2653-2665.

24. Wallach JA: Biodegradable polymers derived from renewable resources: highly branched copolymers of itaconic anhydride. In Polym. Sci. Edited by Storrs CT: University of Connecticut; 2000.

25. Meier MAR, Metzger JO, Schubert US: Plant oil renewable resources as green alternatives in polymer science. Chem. Soc. Rev. 2007, 36:1788-17802.

26. Papanu VD: Amide-imide derivatives of homopolymers of itaconic anhydride having antitumor activity. application: EP. USA: Monsanto Co; 1983:18.

27. Milovanovic MB, Trifunovic SS, Katsikas L, Popovic IG: Preparation and modification of itaconic anhydride-methyl methacrylate copolymers. J. Serb. Chem. Soc. 2007, 72(12):1507-1514.

28. Cismaru L, Hamaide T, Popa M: Itaconic anhydride based amphiphilic copolymers: synthesis, characterization and stabilization of carboxyl functionalized. PEGylated nanoparticles. Eur. Polym. J. 2007, 43:4843-4851.

29. Shang S, Huang SJ, Weiss RA: Synthesis and characterization of itaconic anhydride and stearyl methacrylate copolymers. Polymer 2009, xxx:1-9.

30. Erbil C, Terlan B, Akdemir O, Gokceoren AT: Monomer reactivity ratios of $\mathrm{N}$-isopropylacrylamide-itaconic acid copolymers at low and high conversions. Eur. Polym. J. 2009, 45:1728-1737.

31. Mormann W, Ferbitz J: Copolymers from tert-butyl methacrylate and itaconic anhydride-reactivity ratios and polymer analogous reactions. Eur. Polym. J. 2003, 39:489-496.

32. Kun RC, Soykan C, Delibas A: Study of free-radical copolymerization of itaconic acid/2-acrylamido-2-methyl-1-propanesulfonic acid and their metal chelates. Eur. Polym. J. 2006, 42:625-637.

33. Bajaj P, Paliwal DK, Gupta AK: Acrylonitrile-acrylic acids copolymers I synthesis and characterization. J. Appl. Polym. Sci. 1993, 49:823-833.

34. Xue W, Champ S, Huglin MB: Observations on some copolymerisations involving $N$-isopropylacrylamide. Polymer 2000, 41:7575-7581.

35. Cowie JMG, McEwen IJ, Yule DJ: The influence of solvent on the apparent reactivity ratios in free radical copolymerisation reactions between itaconic acid and 2-hydroxyethyl acrylate. Eur. Polym. J. 2000, 36:1795-1803.

36. Uyanık N, Erbil C: Monomer reactivity ratios of itaconic acid and acrylamide copolymers determined by using potentiometric titration method. Eur. Polym. J. 2000, 36:2651-2654.

37. Erbil C, Ozdemir S, Uyanık N: Determination of the monomer reactivity ratios for copolymerization of itaconic acid and acrylamide by conductometric titration method. Polymer 2000 41:1391-1394.

38. Virtanen J, Tenhu H: Studies on copolymerization of $\mathrm{N}$ isopropylacrylamide and glycidyl methacrylate. J. Polym. Sci. Pol. Chem. 2001, 39:3716-3725.

39. Devasia R, Nair CPR, Ninan KN: Copolymerization of acrylonitrile with itaconic acid in dimethylformamide: effect of triethylamine. Eur. Polym. J. 2003, 39:537-544.

40. Patel MV, Dolia MB, Patel JN, Patel RM: Synthesis and characterization of novel acrylic copolymers: determination of monomer reactivity ratios and biological activity. React. Funct. Polym. 2005, 65:195-204. 
41. Pekel N, S_ahiner N, Guven O, Rizaev ZMO: Synthesis and characterization of $\mathrm{N}$-vinylimidazole-ethyl methacrylate copolymers and determination of monomer reactivity ratios. Eur. Polym. J. 2001, 37:2443-2451.

42. Save NS, Jassal M, Agrawal AK: Stimuli sensitive copolymer poly ( $N$-tert-butylacrylamide-ran-acrylamide): synthesis and characterization. J. Appl. Polym. Sci. 2005, 95:672-680.

43. Oishi T: Polymerizations and copolymerizations of $\mathrm{N}$-(4-substituted phenyl)itaconimides. Polym. J. 1980, 12:719-727.

44. Urzua M, Opazo A, Gargallo L, Radić D: Poly(N-1-alkylitaconamic acids) /poly(N-vinyl-2-pyrrolidone) blends. Polym. Bull. 1998, 40:63-67.

45. Shang S, Huang SJ, Weiss RA: Synthesis and characterization of itaconic anhydride and stearyl methacrylate copolymers. Polymer 2009, 50:3119-3127.

46. Ehrenstein GW, Riedel G, Trawiel P: Thermal analysis of plastics: Theory and practice. Hanser Gardner Publications 2004, ISBN-13:9781569903629.

47. Krušić KM, Džunuzović E, Trifunović S, Filipović J: Polyacrylamide and poly (itaconic acid) complexes. Eur. Polym. J. 2004, 40:793-798.

48. Fellows CM: Preliminary observations on the copolymerisation of acceptor monomer:donor monomer systems under microwave irradiation. Central Eur J Chem 2005, 3:40-52.

doi:10.1186/1752-153X-6-85

Cite this article as: Osman et al:: Microwave synthesis and thermal properties of polyacrylate derivatives containing itaconic anhydride moieties. Chemistry Central Journal 2012 6:85.

\section{Publish with ChemistryCentral and every scientist can read your work free of charge \\ "Open access provides opportunities to our colleagues in other parts of the globe, by allowing anyone to view the content free of charge." \\ W. Jeffery Hurst, The Hershey Company.}

- available free of charge to the entire scientific community - peer reviewed and published immediately upon acceptance

- cited in PubMed and archived on PubMed Central

- yours - you keep the copyright

Submit your manuscript here:

http://www.chemistrycentral.com/manuscript/<smiles>c1ccccc1</smiles>

Chemistry Central 